\title{
ESBOZO DEL DEPARTAMENTO DE PREHISTORIA Y ARQUEOLOGÍA DE LA UNIVERSIDAD DE SEVILLA DE HACE TREINTA AÑOS
}

\author{
OUTLINE OF THE DEPARTMENT OF PREHISTORY AND ARCHAEOLOGY \\ AT THE UNIVERSITY OF SEVILLA THIRTY YEARS AGO
}

\author{
MANUEL PELLICER CATALÁN*
}

\begin{abstract}
Resumen: En este trabajo se explica la creación del Departamento de Prehistoria y Arqueología de la Universidad de Sevilla. La cátedra de Historia de España antigua y media se dividió en tres departamentos, siendo dirigido el de Prehistoria y Arqueología por el profesor A. Blanco desde 1959 hasta 1973, y por el profesor Pellicer desde 1975 hasta 1992, fecha de su jubilación. En este trabajo se describen las vicisitudes, los cambios y las actividades docentes de esos momentos. Palabras clave: Departamento de Prehistoria y Arqueología, Universidad de Sevilla, creación, historia.
\end{abstract}

En este homenaje al profesor Bendala Galán presento un esbozo de mis recuerdos de aquella época en que él era profesor del Departamento de Prehistoria y Arqueología de la Universidad de Sevilla y del que yo me hice cargo.

En la segunda mitad del siglo XIX, en España la arqueología histórica estaba mayoritariamente cultivada por eruditos locales, y la prehistórica por geólogos profesionales directamente influenciados por sus colegas franceses. Las desordenadas excavaciones arqueológicas del XIX fueron controladas en España con la ley de 1911, que organizó las investigaciones, prohibiendo la venta y exportación de bienes arqueológicos y gestionando los trabajos de campo la Junta Superior de Excavaciones y Antigüedades, creada en 1912. Las investigaciones prehistóricas relativas al Paleolítico se organizaron

\footnotetext{
* Universidad de Sevilla
}

\begin{abstract}
This paper presents an overview of the creation of the Department of Prehistory and Archaeology of the University of Seville. The teaching of the Ancient and Middle History of Spain was divided between three departments. The Department of Prehistory and Archaeology was directed by Professor A. Blanco from 1959 to 1973, and by Professor Pellicer from 1975 to 1992, year in which he retired. This overview describes the vicissitudes, changes and teaching of those times. Key words: Department of Prehistory and Archaeology, University of Seville, origin, history
\end{abstract}

con la creación de la Comisión de Investigaciones Paleontológicas y Prehistóricas. Entre tanto, surgieron las primeras cátedras de Prehistoria y Arqueología en las universidades de Barcelona, ocupada por P. Bosch en 1916, y de Madrid, ocupada por H. Obermaier en 1922. En la escuela madrileña del paleolitista $H$. Obermaier destacaron J. Pérez de Barradas, J. Martínez Santa Olalla, A. García y Bellido y M. Almagro, mientras que en la catalana del arqueólogo P. Bosch sobresalieron L. Pericot, J. Serra y A. del Castillo, entre otros, cuya formación se completó como becarios en universidades alemanas. Conforme se creaban cátedras de Prehistoria y de Arqueología, las titulaciones y contenidos carecían de unidad en las once universidades existentes y, al crearse los departamentos, se desdoblaron las titulaciones y contenidos de las cátedras.

En el caso concreto de la Universidad de Sevilla, J.M. Carriazo, formado en el Centro de Estudios Históricos de Madrid, había sido nombrado catedrático 
de Historia antigua y media en 1927, adquiriendo cierto renombre, como prehistoriador con su publicación en 1947 sobre la Edad del Bronce en la monumental Historia de España (I, 1: 755-852) dirigida por R. Menéndez Pidal, y como arqueólogo por sus excavaciones en Itálica $(1934 ; 1935 ; 1961 ; 1963)$ y en el poblado tartesio del Carambolo (1959; 1960; 1963; 1970; 1973). Su estrecho colaborador, como arqueólogo de campo, fue siempre F. Collantes de Terán (1977), cuya tesis sobre la topografía de la Sevilla antigua y medieval sirvió de base a J.M. Carriazo (1980) para su Protohistoria de Sevilla.

Al jubilarse J.M. Carriazo en 1969, la cátedra de España Antigua y Media se desdobló en tres departamentos: Prehistoria y Arqueología, cuya cátedra fue ocupada por A. Blanco, Historia Antigua, cuya cátedra fue ocupada por F. Presedo, e Historia Medieval, cuya cátedra fue ocupada por M. A. Ladero en 1975.

En los años sesenta hubo lamentables desavenencias de J.M. Carriazo con A. Blanco y con A. García Bellido por competencias en investigaciones. Nombrado J.M. Carriazo Comisario del Distrito Universitario de Sevilla en 1956 y jubilado en 1969, A. Blanco, catedrático de Arqueología de Sevilla, intentó sustituirlo, produciéndose cierto enfrentamiento entre los dos. Legalmente el cargo de Comisario correspondía al catedrático de Arqueología, o, si no existía tal catedrático, al de materia similar.

Descubierto casualmente el tesoro tartesio del Carambolo en 1958, J.M. Carriazo inició las excavaciones en el yacimiento, publicando someramente el hallazgo en el Illustrated London News de enero de 1959 , a la vez que aparecía un documentado trabajo sobre el tema, firmado por E. Kukahn, profesor de la Universidad de Bonn y miembro del Instituto Arqueológico Alemán de Madrid, y por A. Blanco (1959). La enemistad entre los dos catedráticos, el jubilado y el sucesor, duró indefinidamente. J.M. Carriazo prosiguió sus excavaciones en el Carambolo hasta la publicación de su monumental memoria sobre los trabajos, y, como director de las excavaciones de Itálica, había publicado someros trabajos.

Por lo que respecta a Itálica, A. García Bellido había solicitado autorización a J.M. Carriazo para revisar directamente la urbanística del yacimiento, publicada en su valiosa obra Colonia Aelia Agusta Italica (1960). En el VIII Congreso Nacional de Arqueología, celebrado en Sevilla y Málaga en 1963, A. García Bellido (1964: 454-460) presentó una comunicación con el título "Las casas de Itálica". J.M. Carriazo insinuó que el plano de Itálica mostrado por el comunicante "había sido pirateado a mansalva con desconocimiento de la propiedad intelectual", contestándole A. García Bellido haber revisado el plano de Itálica en 1955 bajo los auspicios del profesor Carriazo, para rectificar las inexactitudes del plano del profesor Wegner de 1954, y, por otra parte, refiriéndose a J.M. Carriazo, proclamó que "quien así habla convendría que se apease ya del alto coturno con el que quiere andar entre arqueólogos, porque todos nos conocemos y sabemos qué coturnos calzamos".

Después de tres decenios de iniciadas las excavaciones en Itálica por J.M. Carriazo, la arqueología hispana echaba de menos, efectivamente, una obra detallada sobre tan interesante yacimiento. Ese vacío de información sobre Itálica se rellenó, en parte, con el librito de A. García Bellido de 1960.

La actuación de J.M. Luzón, como director de las excavaciones de Itálica en los años setenta, supuso un notable avance en el conocimiento de la Nova Urbs con la excavación de mansiones, vías, registros de cloacas, parte de la muralla septentrional y teatro, utilizando valiente e inteligentemente maquinaria pesada para levantar la capa superficial estéril (Luzón 1975; 1982). Por otra parte, J.M. Luzón (1973) realizó el primer corte estratigráfico de la Uetus Urbs en la plaza del Pajar de Artillo, en el centro de Santiponce, donde había aparecido un tesorillo de monedas áureas romanas. La estratigrafía se fechó a partir del 206 a.C., según el relato de Apiano, pero, cuando yo me encargué de las excavaciones de Itálica, revisé el material, observando que el de los dos estratos inferiores era prerromano, de los siglos IV-III a.C. (Pellicer 1982; 1998).

En el Carambolo J.M. Carriazo trabajó primeramente en el lugar donde había aparecido el tesoro, considerado un fondo de cabaña, y, ante los problemas que presentaba el complejo yacimiento, requirió la ayuda y el consejo de J. Maluquer (1992; 1994).

En 1966, siendo yo director de la sección de arqueología del recién creado Instituto Central de Restauración de Madrid, la Dirección General de Bellas Artes me encargó el montaje de una gran exposición de cerámica española desde la Prehistoria hasta nuestros días, para la cual solicité a J.M. Carriazo un lote de cerámicas variadas, causando sensación el llamado tipo Carambolo decorado con geometrismos pintados.

El Instituto Arqueológico Alemán de Madrid excavaba entonces el yacimiento romano de Munigua (Villanueva del Río y Minas, Sevilla), cuyo director de la excavación era K. Raddatz, quien solicitó de J.M. Carriazo autorización para realizar un corte estratigráfico en Carmona (Carriazo y Raddatz 1960; 1961). La 
excavación de Raddatz fue del máximo interés, habiéndose obtenido por primera vez en Andalucía occidental una estratigrafía de una potencia de $4 \mathrm{~m}$ con cinco estratos correspondientes al Bronce Final, al Período Orientalizante y al Púnico-Turdetano. Unos años después, en el $V$ Simposio de Prehistoria Peninsular, dedicado a Tartessos y celebrado en Jerez de la Frontera en 1968, tuve la ocasión de revisar el corte estratigráfico de Carmona (1969) y corregir la cronología de los estratos inferiores, según los resultados de mis excavaciones en el poblado protohistórico de Tutugi (Galera, Granada) (Pellicer y Schüle 1962; 1963; 1966), en la necrópolis fenicia de Almuñécar (Pellicer 1963) y en la colonia fenicia de Toscanos (Torre del Mar, Málaga) (Schubart y otros 1964; 1969).

Al obtener A. Blanco la cátedra sevillana en 1959, creó un departamento de Arqueología clásica, orientado también hacia las investigaciones del mundo orientalizante (Blanco 1960; 1964; 1980; 1983; 1984; Blanco y otros $1969 ; 1970 ; 1975 ; 1981 ; 1982 ; 1985)$ y hacia el mundo romano, especialmente italicense (Blanco 1975; 1978; Blanco y Luzón 1974). A. Blanco, licenciado en Filología Clásica y doctorado bajo la dirección de A. García Bellido en 1947 con una tesis sobre la minería y metalurgia antigua, estuvo becado en las universidades de Oxford, como discípulo de Beazley (1947-1949) y de Bonn, como discípulo de Jacobsthal y Langlotz (1954-1959). En los años cincuenta fue profesor adjunto de Arqueología Clásica con su maestro A. García Bellido en la Universidad Complutense de Madrid, convirtiéndose en la máxima figura española en toréutica orientalizante (Blanco 1956; 1960).

En 1974, fallecido A. García Bellido y habiendo quedado libre la cátedra de Arqueología clásica de la Complutense, A. Blanco la obtuvo por traslado, saliendo entonces a concurso la cátedra de la Universidad sevillana, a la que yo concursé y la que obtuve. A la sazón, J. Maluquer, catedrático de la Universidad de Barcelona y nombrado Comisario General de Excavaciones Arqueológicas (1974-1976), me insistió en que firmara la cátedra de Sevilla para encargarme de la excavación de Cerro Macareno, extraordinario yacimiento tartesio en trance de destrucción. Acepté su ruego, comunicándole que no podría presentarme en Sevilla hasta el curso 1975-1976, por mi labor pendiente de docencia e investigación en la Universidad de La Laguna, donde yo era catedrático.

En 1975 llegué a Sevilla y advertí en el departamento de Prehistoria y Arqueología ciertas anomalías. A. Blanco había llevado a su departamento de Madrid a dos profesores doctores del departamento sevillano,
L. Abad y P. León, y, por otra parte, la asignatura de Prehistoria estaba transferida al Departamento de Historia de América y Antropología, explicando la materia I. Moreno en Sevilla y S. Rodríguez Becerra en el Colegio Universitario de Cádiz, dependiente de Sevilla. Mis esfuerzos por recuperar la materia de Prehistoria para el Departamento de Prehistoria y Arqueología fueron vanos en principio; pero a través del rectorado se consiguió, arguyendo yo que la Prehistoria correspondía al Departamento de Prehistoria y Arqueología $\mathrm{y}$, por otra parte, que el programa explicado por el Departamento de Antropología era absolutamente inadecuado.

Cubierta la docencia de Arqueología por mí y por los doctores o licenciados J.M. Luzón, M. Bendala, F. Chaves, R. Corzo y M.L. La Bandera, discípulos de A. Blanco, y sin profesores suficientemente preparados en Prehistoria, en el curso 1975-1976 llegó para impartir la materia A. Tejera, a quien yo dirigía la Tesis Doctoral, y, en el curso siguiente, la profesora agregada de Prehistoria P. Acosta, trasladada por concurso a la Universidad de Sevilla.

E. Vallespí, especialista en Paleolítico e industrias líticas, profesor titular de la Universidad de Oviedo, completó el profesorado de Prehistoria en Sevilla. El profesor Vallespí formó un grupo de arqueólogos, dando a conocer con sus investigaciones el Paleolítico inferior y medio, prácticamente inédito, de las terrazas del bajo Guadalquivir y la industria lítica de diferentes yacimientos prospectados o excavados de Andalucía occidental (Vallespí 1986; 1988; 1995).

La docencia y la investigación de Prehistoria y Arqueología en la Universidad de Sevilla y en los colegios universitarios de Cádiz y La Rábida se normalizó en el curso 1976-1977 con los profesores M. Pellicer, P. Acosta, E. Vallespí, J.M. Luzón, M. Bendala, F. Chaves, R. Corzo, M. L. La Bandera, A. Tejera, R. Cabrero y R. Cruz-Auñón. Por falta de espacio en la Universidad sevillana, la Prehistoria se impartió en el edificio de Puerta Osario, donde se instaló el laboratorio de Arqueología.

En el Colegio Universitario de Cádiz la Arqueología era impartida por las licenciadas en Arte M.D. López e I. Pérez y, a partir de 1976, la Prehistoria y la Arqueología por M. Pellicer, P. Acosta, A. Tejera y L. Mora-Figueroa. Poco después impartieron Prehistoria en Cádiz sucesivamente M. Belén, como profesora titular, J. Luis Escacena, A. Caro y J. Ramos. M. Belén, formada en la Complutense con el profesor M. Almagro Basch, tuvo que someterse a una nueva oposición a la titularidad de Prehistoria de Sevilla, donde alivió la 
docencia, ejerciendo una prestigiosa investigación en Protohistoria (Belén 1976; 1987; 1993; 2006), habiéndose encargado de la dirección de las excavaciones de Carmona con un preparado equipo de la Universidad de Sevilla (Belén 1994; 1997).

J.L. Escacena obtuvo la titularidad de Prehistoria del departamento sevillano, habiendo sido coautor de la publicación de Cerro Macareno (Pellicer y otros 1983), destacando por sus investigaciones sobre el Neolítico de la Marismilla (Escacena 1987; 1996), el Bronce del Berrueco de Medina-Sidonia (Escacena y De Frutos 1985), el período orientalizante de Coria del Río (Escacena e Izquierdo 2001; Escacena y otros 2005) y sobre protohistoria de Andalucía occidental.

A. Caro, docente al principio en el colegio universitario de La Rábida, pasó a la Universidad de Cádiz, donde obtuvo la titularidad de Prehistoria, habiéndose dedicado intensamente a la investigación arqueológica de Lebrija (Caro y otros 1987; 1991; 1995).

Al ocuparme del Departamento de Prehistoria y Arqueología de Sevilla, me documenté intensamente sobre las investigaciones arqueológicas de Andalucía occidental, para programar excavaciones estratigráficas a realizar sobre el Neolítico, poco conocido pero con grandes perspectivas, y sobre el Calcolítico, del que se conocía el megalitismo. El Bronce Pleno se presentaba como un interrogante a resolver. En la Protohistoria del Bronce reciente, orientalizante y turdetano había que poner orden y, respecto al mundo romano, había que trabajar en Itálica siguiendo la pauta iniciada por J.M. Luzón. Las múltiples prospecciones llevadas a cabo por el departamento en los años setenta y ochenta, relativas a diferentes horizontes culturales desde el Paleolítico a la romanización, sirvieron a los miembros del departamento, y especialmente a los alumnos, como prácticas absolutamente necesarias para su formación arqueológica.

La Cueva Chica de Santiago de Cazalla de la Sierra (Sevilla) fue prospectada con la ayuda de R. Corzo en 1976, advirtiéndose un rico yacimiento neolítico y calcolítico de especial importancia por su situación en plena Sierra Morena, mal conocida en estos horizontes culturales. Entre los años 1976 y 1980 se efectuaron tres campañas de excavaciones bajo la dirección de $\mathrm{P}$. Acosta, con la participación de los profesores M. Pellicer, R. Corzo, V. Hurtado, L. MoraFigueroa, R. Cabrero, J.L. Escacena, M.M. Ruiz y M.L. de la Bandera, y los alumnos J. Cuenda, J. Fernández Lacomba y E. Núñez. Se obtuvo una estratigrafía de siete niveles en dos cortes de una potencia de 2'50 m, correspondientes a horizontes culturales de Neolítico,
Calcolítico y Bronce Final, exponentes de la Prehistoria del sistema cultural donde sensiblemente solo se conocía por algún conjunto megalítico estudiado por los Leisner (1943) y por C. Cerdán y los Leisner (1952), y por algunos poblados prospectados por R. Cabrero posteriormente (Cabrero 1985; 1986; 1987; 1988; Cabrero y Florido 1988) y J.A. Pérez Macías (1987; 1994), así como por V. Hurtado y L. García (1994) y por el departamento de Arqueología de la Universidad de Córdoba.

Los datos ofrecidos por el C-14 en la cueva excavada han documentado un Neolítico antiguo de la segunda mitad del VI milenio y principios del V milenio a.C., un Neolítico pleno de la segunda mitad del V milenio a.C., un Neolítico reciente de la segunda mitad del IV milenio a.C., así como un Calcolítico relacionado estrechamente con Portugal (Acosta 1983; 1986; Pellicer y Acosta 1982). La fauna fue estudiada por E. Bernáldez.

En los años ochenta se solicitó la publicación de la excavación a la Dirección General de Bienes Culturales de la Junta de Andalucía, siendo denegada por haber sido efectuada la excavación con anterioridad a la transferencia de cultura a la Junta. El documento-trabajo redactado por P. Acosta y M. Pellicer quedó inconcluso por el fallecimiento de la profesora, y en la actualidad está en preparación por M. Pellicer, J.L. Escacena y R. Cruz-Auñón. La cueva de la Dehesilla (Algar, Cádiz), fue visitada por indicación de L. Perdigones y, obtenida la autorización para su excavación, se realizaron dos campañas de excavaciones en 1977 y 1981, dirigidas por P. Acosta, con la participación de M. Pellicer, F. Amores, J.L. Escacena, R. Cruz-Auñón, M.M. Ruiz, E. Rivero, J. Cuenda, E. Núñez, C. De Bock y A. Hueso.

La estratigrafía, de una potencia de 3'40 m, entregó una sucesión cultural de Neolítico antiguo, pleno, reciente y Calcolítico. El abundante material de artefactos, especialmente cerámicos, y la planimetría fueron dibujados por E. Núñez, F. Lacomba, F. Amores y J. Cuenda, y las estadísticas de los materiales, sincrónicas y diacrónicas fueron efectuadas por M. Pellicer. La fauna estudiada por K. Boesneck y A. von den Driench (1980) y la estratigrafía fue fechada por el profesor Gakushuin, de la Universidad de Tokio, y por la Universidad de Granada, definiendo un Neolítico antiguo fechable desde la primera mitad el VI milenio a mediados del V a.C.. El yacimiento se publicó parcialmente en varios artículos (Acosta 1980; 1987; 1990). Habiendo solicitado su publicación completa a la Junta de Andalucía, obtuvimos igualmente la negativa por ser la excavación anterior a las transferencias, por lo que tuvimos que recurrir al Instituto de Estudios Jerezanos, 
que gentilmente accedió a su publicación, aunque con deficiencias de formato, excesivamente reducido (Acosta y Pellicer 1990).

La cueva del Parralejo (San José del Valle, Cádiz) fue prospectada por indicación de L. Perdigones, hallándose totalmente removida por excavaciones clandestinas de los americanos de la Base de Rota y, también, por la extracción de murcielaguina para abono por parte de los agricultores de la zona. Dado el interés de la cerámica neolítica de superficie, y solicitada autorización, practicamos un sondeo, resultando la estratigrafía revuelta e inaprovechable. El equipo estuvo formado por M. Pellicer, M. Bendala, L. Mora-Figueroa y L. Perdigones, con la ayuda de tres obreros.

La cueva de Nerja (Málaga) es uno de los yacimientos prehistóricos andaluces más interesantes por su estratigrafía del Paleolítico superior, Epipaleolítico, Neolítico y Calcolítico. Desde su descubrimiento en 1959 fue excavada por M. Pellicer (1963; Hopf y Pellicer 1970), A.N. Cuadra Salcedo, J.M. Muñoz Gambero y A. Arribas, quedando estos trabajos inéditos.

Constituido el Patronato de la Cueva, la inmensa cavidad se dedicó al turismo y, ante su deterioro medioambiental, se creó en 1978 una Comisión Científica para su protección y estudio, formada por M. Pellicer (Neolítico-Calcolítico), F. Jordá (Paleolítico), M. Hoyos (Geología), F. Marín (Biología) y J.L. Sanchidrián (arte rupestre). Esta Comisión publicó hasta 1996 seis volúmenes de "Trabajos sobre la cueva de Nerja": 1 (Pellicer y Jordá 1986), 2 (Marín 1991), 3 (Carrasco 1993), 4 (Sanchidrián 1994), 5 (Morales y Pellicer 1995) y 6 (Pellicer y Acosta 1996, con la colaboración de M. García y S. Jiménez: antropología física, J.M. Rodanés: industria ósea y A. Cava; industria lítica tallada).

El departamento realizó en Nerja siete campañas de excavaciones desde 1979 a 1986, subvencionadas por el Patronato y dirigidas por M. Pellicer y P. Acosta, en las que participaron profesores y alumnos de las universidades de Sevilla, Málaga y Cádiz: J. Rodríguez Vidal, A. Pérez Macías, J. Ramos, Bartolomé Ruiz, V. Hurtado, F. Amores, M.M. Ruiz Delgado, A. Caro, E. Rivero, I. Rodríguez Temiño, Eduardo Ferrer, J. Fernández, J. Cuenda, Ester Núñez, A. Hueso, C. Pereda, F. Martínez, R. Rodríguez, I. Franco, P. Fernández, M. Vera, I. Santana, M.R. Ojeda, S. Rodríguez de Guzmán, J. Mancebo, A. Pérez Paz, F. García del Junco, M.L. Lavado, P. Cáceres, C. Barroso y Margarita Díaz.

Se abrieron tres cortes en la sala de la Mina, muy afectada por anteriores excavaciones, $\mathrm{y}$ otros tres en la sala de la Torca, profundizando hasta el Epipaleolítico. El Paleolítico fue estudiado por el equipo de F. Jordá (1986) y la fauna por el equipo de A. Morales (1995). Los análisis de C-14, efectuados por los laboratorios de la Universidad de Tokio y de Groeningen, entregaron unas dataciones del VII milenio a.C. para el Epipaleolítico, VI milenio a.C. para el Neolítico antiguo, V milenio a.C. para el Neolítico medio y IV milenio a.C. para el reciente.

En 1988 la Dirección General de Bienes Culturales desautorizó arbitrariamente las excavaciones en la Cueva con el sorprendente argumento de "mantener el yacimiento en reserva, dado su peculiar interés". Ante esta insólita prohibición, renuncié a la dirección de la Comisión de Investigación del Patronato de la Cueva.

Lebrija (Sevilla) había sido minuciosamente prospectada por A. Caro en su Tesina (1991) y en trabajos posteriores, pero en la calla Alcazaba, ladera del castillo, había aparecido cerámica prehistórica y protohistórica. Solicitada la autorización, A. Caro, P. Acosta y J.L. Escacena practicaron un corte estratigráfico de varios metros de potencia, hallando una sucesión cultural desde el Neolítico hasta el Medievo con algunos hiatos (Caro y otros 1987; Caro 1990). Con el fallecimiento de A. Caro el estudio permanece todavía inédito.

En los años ochenta el geólogo L. Menanteau descubrió un extraordinario poblado calcolítico en Cantillana, a la orilla del Guadalquivir, llamado Patronatas o La Morita. El departamento efectuó un sondeo dirigido por P. Acosta con la participación de R. Cabrero, R. Cruz-Auñón, V. Hurtado y otros (Acosta y otros 1987). La estratigrafía entregó los típicos platos o fuentes carenadas y los de borde almendrado, anteriormente conocidos en Valencina de la Concepción (Ruiz Mata 1975) y en el Alentejo portugués.

El Cerro Macareno fue excavado en el verano de 1976 con participación plena del departamento. Había sido descubierto por A. Cuenca en 1971, siendo explotado como cantera de áridos por el contratista $\mathrm{M}$. Castro y propiedad de la Marquesa de Valencina. En $1975 \mathrm{~J}$. Maluquer, Comisario Nacional de Excavaciones, había autorizado la excavación a varios arqueólogos de la Universidad Autónoma de Madrid (J. Sánchez Meseguer, D. Ruiz Mata y J.C. Martín de la Cruz), del Museo Arqueológico de Sevilla (F. Fernández Gómez) y de la Universidad de Sevilla (R. Corzo). J.C. Martín presentó como Tesina en el departamento sevillano el perfil estratigráfico $\mathrm{F}$ del yacimiento (Martín de la Cruz 1976). J. Maluquer quiso integrarme en uno de los equipos, pero preferí realizar la excavación según mi proyecto. Declarado el yacimiento "bien de utilidad 
pública", se le prohibió al contratista la extracción de áridos y la destrucción del cerro.

Confeccioné la planimetría del yacimiento en una superficie de 5 ha, dividiéndolo en tres zonas. La zona A, situada al SE, permanecía intacta en 1 ha; la zona B, situada al NE y de unos $8000 \mathrm{~m}^{2}$, se hallaba con la superficie removida, donde excavaban los equipos arqueológicos; y la zona $\mathrm{C}$, de 3 ha, entre las otras dos zonas y en el centro, estaba totalmente destruida. Mi proyecto consistió simplemente en la realización de un corte estratigráfico de 4 por 4'50 m de superficie en la periferia sureste de la zona A, que se conservaba intacta. Mi equipo estuvo compuesto por tres profesores de clases prácticas del departamento, M. Bendala, R. Corzo y M.L. de la Bandera, y por 15 licenciados y estudiantes: J.L. Escacena, R. Cabrero, V. Hurtado, F. Amores, E. Núñez, L. Perdigones, J. Fernández, F. Rubio, S. Fajarnes, S. Tossato, C. de Bock, T. Cárdenas, A. Oliva, G. Osuna y E. Rivero. Además, cinco obreros.

El trabajo se dividió en cuatro secciones: excavación, topografía, cribado y limpieza y signatura de materiales. Los lotes o materiales prototípicos inventariados, con un total de 2.395 elementos, fueron transportados provisionalmente al laboratorio instalado en la biblioteca de arte de la Universidad, donde fueron dibujados por E. Núñez, F. Amores, J. Fernández Lacomba $\mathrm{y}$ algún otro alumno.

En la excavación se detectaron 9 estratos y 26 niveles en una potencia de 7'50 m, correspondientes el inferior, I, al Bronce final, los niveles II-III al Período Orientalizante, el IV al Prototurdetano, el V al Turdetano antiguo, los niveles VI-VII al Turdetano pleno, el VIII al Turdetano reciente y el IX a inicios de Época Romana republicana. Con el corte estratigráfico del Cerro Macareno (Pellicer y otros 1983) se había conseguido una tipología y cronología bastante precisa de las estructuras, artefactos y ecofactos del bajo Guadalquivir tartesio y turdetano, fechados ambos periodos según las cerámicas fenicias y áticas, las ánforas (fenicias, púnicas, corintias y romanas) y la cerámica campaniense. La numismática romana fue estudiada por F. Chaves (1980) y la fauna por A. von den Driesch (1985).

A partir del curso 1976-1977 se proyectó y organizó en el departamento un vasto programa de investigación prehistórica (Neolítico, Calcolítico y Bronce), protohistórica (fenicia, orientalizante y turdetana) y romana en Itálica, cuya dirección estaba a cargo de J.M. Luzón. Mediante prospecciones y cartas arqueológicas por parte de las tesinas de los licenciados fueron detectándose y localizándose centenares de yacimientos, seleccionándose algunos para su posible excavación y estudio. El Paleolítico fue incluido en el programa con la presencia del profesor E. Vallespí, dedicado al estudio de la industria lítica tallada de las terrazas del Guadalquivir y de algunos yacimientos de Andalucía occidental (Vallespí 1986, 1988, 1995).

El Institut of Archaeometry Studies de Londres se interesó en 1973 por el estudio de la minería y metalurgia calcolíticas de Riotinto, consideradas por B. Rothenberg el foco primigenio de Europa. B. Rothenberg era un judío que había trabajado con equipos arqueológicos de Israel en el Sinaí como fotógrafo (Rothenberg 1979), y especialmente en el yacimiento calcolítico de Timna (Rothenberg 1972; Conrad y Rothenberg 1980), encargándose de los hallazgos en el Nechustan Pavillon de Israel. En mis conversaciones con él en Riotinto, observé que tenía conocimientos de minería y metalurgia antiguas, pero, en realidad, era un profano en Arqueología, y especialmente en cerámica. En su trabajo de campo contrataba a un técnico de excavación, Philip Andrews, sorprendentemente no arqueólogo. A principios de los años 80 la empresa Volkswagen me solicitó, a través del profesor H.G. Niemeyer, un informe arqueológico sobre B. Rothenberg, cuyas excavaciones subvencionaba la empresa. El informe no laudatorio ocasionó el cese de las subvenciones.

En el verano de 1976 A. Blanco y B. Rothenberg me habían visitado en la excavación de Cerro Macareno, invitándome a trabajar con ellos en su proyecto de Riotinto. En 1977 me encargaron de la excavación del yacimiento de Quebrantahuesos, que era una prolongación del Cerro Salomón excavado por A. Blanco, J.M. Luzón y D. Ruiz (1970). En la excavación de Quebrantahuesos colaboraron A. Tejera, A. Canto, dos alumnos de la Universidad Autónoma de Madrid y tres de la de Sevilla: F. Rubio, L. Bernáldez y R. Sánchez. Quebrantahuesos correspondía a un poblado minero metalúrgico orientalizante y turdetano de los siglos VII-IV a.C. (Pellicer 1983).

En 1978 dirigí la excavación del poblado de Chinflón (Zalamea la Real, Huelva), participando en los trabajos V. Hurtado, como codirector, J.L. Escacena, J. Ramón, J. Cuenda, E. Rivero, P. Florido, F. Amores y M. Hunt, todos ellos formados en el departamento de la Universidad de Sevilla. El yacimiento era superficial y de corta vida, correspondiente exclusivamente al Bronce final precolonial, sin intrusiones calcolíticas ni orientalizantes. Terminado el estudio del yacimiento, B. Rothenberg me sugirió que hiciera constar sus orígenes calcolíticos, a lo que me opuse por no 
haber aparecido ese horizonte. Sin atender a los datos científicos aportados por los materiales arqueológicos y especialmente cerámicos de la excavación, A. Blanco y B. Rothenberg, relacionando erróneamente el poblado de Chinflón del Bronce final con el contiguo grupo dolménico del Pozuelo, rehusaron incluir nuestro trabajo (Pellicer y V. Hurtado 1980) en su publicación sobre Exploración Arqueometalúrgica de Huelva (1981), por no contar con las teorías apriorísticas de su proyecto.

En 1980 juzgué conveniente repetir en Carmona el corte estratigráfico practicado por K. Raddatz (Carriazo y Raddatz 1960), para revisar la estratigrafía del Bronce reciente, del Período Orientalizante y de la Etapa Turdetana, fechada esta última excesivamente baja, y para relacionarla con la del Cerro Macareno. En la excavación de Carmona participó prácticamente todo el departamento de Sevilla: M. Pellicer, P. Acosta, F. Amores, M.L. de la Bandera, R. Cabrero, V. Hurtado, R. Cruz-Auñón, F. Chaves, J.L. Escacena, M.M. Ruiz, E. Rivero, J. Cuenda, J.M. Rodríguez, F. Serrano, P. Florido, E. Núñez, J. Morales, M. Valor e I. Rodríguez.

La excavación se inició junto al antiguo corte de Raddatz, alcanzando la estratigrafía una potencia de 7’50 m, con diez niveles del Calcolítico, Fenicio u Orientalizante e Iberopúnico, algunos alterados por las fosas de cimentación de los gruesos muros (Pellicer y Amores 1985). La riqueza de la cerámica fenicia y las ánforas de los estratos inferiores sugerían la existencia de un sector fenicio, relacionado con la próxima necrópolis de la Cruz del Negro (Amores y otros 1997; 1999; 2001). No habiendo localizado en este corte CA80/A el Bronce reciente del corte de K. Raddatz, abrimos otro corte en el perímetro sureste de Carmona, en el Picacho, donde localizamos ese horizonte.

En 1977 fui nombrado director de las excavaciones de Itálica, suponiéndome una contrariedad por la intensa labor de mis proyectos de excavación y por la docencia en la Universidad de Sevilla y en el Colegio Universitario de Cádiz. En principio, me informé sobre el transcendente yacimiento con toda la bibliografía posible, para preparar un proyecto adecuado, consistente en la delimitación de todo el perímetro amurallado de la ciudad, incluyendo la Vetus y la Nova Vrbs, todavía no constatado. En segundo lugar, me interesaba la obtención de una correcta estratigrafía, porque tenía severas dudas sobre la rectitud cronológica aplicada al origen del yacimiento y, en tercer lugar, sentía curiosidad por una estructura situada extramuros y al oeste de la Nova Vrbs.

J.M. Benjumea, Delegado Provincial de Excavaciones, me comunicó que se había comprado, en la calle Moret 15 de Santiponce, la casa donde había aparecido la famosa Venus, cuya cabeza era necesario recuperar..., proyecto de excavación incluible en el mío.

A pesar de que era común creencia la fecha del 206 a.C. aplicada a la fundación de Itálica, según el texto de Apiano (Iber. 38), existían en la "Colección Lebrija" varios vasos griegos de los siglos IV-III a.C., procedentes, al parecer, de Itálica (León 1976). En el Museo Arqueológico de Sevilla se exhibía una ánfora completa, clasificada romana del tipo Dressel 1, que, en realidad, era corintia del siglo IV-III a.C. Después de mi excavación en el Cerro Macareno (Pellicer 1978; 1982; Pellicer y otros 1983), y según su estratigrafía y su cronología bastante precisa, observé que los horizontes culturales y la cronología aplicada a la estratigrafía del Pajar de Artillo de Santiponce (Luzón 1973), no era correcta en los dos estratos inferiores, cuyos inicios turdetanos había que elevarlos, al menos, en dos siglos, y, por otra parte, observé igualmente que el supuesto templo romano capitolino de los Palacios de Santiponce (Bendala 1975; 1982) presentaba una estructura no templaria, y la abundante cerámica hallada, especialmente las ánforas, eran iberopúnicas prerromanas de los siglos IV-III a.C., y en consecuencia, las estructuras excavadas correspondían a unas tabernae o almacenes turdetanos, afirmación no admitida incomprensiblemente en las Primeras Jornadas sobre Excavaciones Arqueológicas en Itálica de 1980 (Pellicer 1982; 1998).

Ante estos precedentes, inicié la excavación estratigráfica en el patio de la casa de la Venus de la calle Moret 15 de Santiponce, en cuyos trabajos participaron profesores y alumnos del departamento: V. Hurtado, M.L. de la Bandera, J.L. Escacena, J. Cuenda, E. Rivero, M.M. Ruiz, E. Núñez, C. de Bock, R.M. Iglesias, P. Florido y C. Espín. La ejecución del corte estratigráfico, que profundizó hasta $5 \mathrm{~m}$ en una superficie de $20 \mathrm{~m}^{2}$, fue ardua debido a las constantes lluvias, a la aparición de un enorme contrafuerte romano de opus caementicium de 1'50 m de grosor, y de varios pozos negros, que dificultaron la estratigrafía, aunque pudieron distinguirse 8 niveles, fechables los inferiores (III), en los siglos IV-III a.C., turdetanos o iberopúnicos, según las ánforas y vasos análogos a los de los niveles 13-15 del Cerro Macareno; los niveles III-V, romanos republicanos, según la cerámica campaniense y las ánforas, y los niveles superiores, VI-VIII, romanos imperiales, según sus ánforas y la terra sigillata (Pellicer y otros 1982).

El objetivo de la delimitación del perímetro de Itálica se consiguió parcialmente, descubriéndose unos $200 \mathrm{~m}$ de muralla con algunas torres en la parte oeste de 
la Nova Vrbs. Efectuados 17 sondeos, se pudieron delimitar tres sectores (Pellicer 1982: 1988). El sector A, situado en el centro y en el noroeste de la Nova Vrbs, corresponde a la zona más excavada, con unas veinte o treinta insulae, construidas en una superficie de 20 ha. El sector B, al oeste del A, de unas 10 ha, correspondiente al Traianeum (León 1988) y a una parte mal conocida, dispone de infraestructuras de cloacas y de tres canalizaciones procedentes de la gran cisterna occidental. El sector C, al oeste de las Termas Mayores, de forma triangular y de una superficie de 8 has, carece de infraestructuras, surcada por las tres canalizaciones de la cisterna. La estructura del extremo oeste del sector C, considerada un cuartel por F. Zevallos y D. de los Ríos (1876), imperceptible en 1977 al inicio de nuestras excavaciones, fue localizada como una mancha blancuzca por fotografía aérea a $250 \mathrm{~m}$ al W-SW de las Termas Mayores. La cisterna, excavada en 1978, construida en opus caementicium y opus latericium, y revocada de opus signinum, de planta rectangular, con tres compartimentos abovedados, dispone de una capacidad de $1000 \mathrm{~m}^{3}$ de agua. En su excavación intervinieron, entre otros, J.L. Escacena, M.M. Ruiz Delgado y F. Amores.

Analizada la estratigrafía de los sedimentos y derrubios de la cisterna, se distinguieron seis estratos, que dieron la cronología de la construcción, uso y derrumbamiento a través de la numismática romana (Chaves 1978), la terra sigillata, las lucernas y las ánforas romanas imperiales, pudiéndose fechar su construcción en el segundo cuarto del siglo II d.C. y su abandono, por las grietas producidas por el bujeo, en la segunda mitad del siglo III d.C., momento en que se iniciaría el derrumbamiento de las bóvedas y, en consecuencia, el abandono paulatino de la Nova Vrbs (Pellicer 1998).

Terminada la excavación de la cisterna, la Confederación Hidrográfica del Guadalquivir, bajo la dirección de M. Palancar (1983), restauró el monumento, según el plano axiométrico efectuado por el arquitecto V. García.

En 1980, obtenida por P. León la agregación de Arqueología de la Universidad de Sevilla, le propuse que se encargase de la dirección de las excavaciones de Itálica, iniciando su interesante proyecto, consistente en el estudio de una zona del sector B, al sur de la Termas Mayores, considerada por J.M. Luzón un complejo foral, donde habían aparecido restos de escultura colosales. P. León, con minuciosa labor, dio a conocer el magnífico Traianeum (León 1988).

Al reorganizar el departamento en 1975, y atendiendo al excelente resultado que yo había conseguido como profesor en las universidades de Granada
(1956-1962) y de La Laguna (1968-1975) dirigiendo tesinas sobre cartas arqueológicas de zonas sensiblemente desconocidas arqueológicamente, impuse este criterio en el departamento sevillano. Con la confección de cartas arqueológicas los recién licenciados tomaron contacto y se familiarizaron con la Arqueología de campo y con los materiales arqueológicos, detectando en Andalucía occidental centenares de yacimientos, catalogándolos culturalmente según sus artefactos y obteniéndose una información necesaria para las investigaciones del departamento.

Se confeccionaron unas veinticinco cartas arqueológicas, correspondientes a diferentes zonas: Valencina de la Concepción por D. Ruiz Mata, Aljarafe y Terrazas del Guadalquivir por J.L. Escacena, Cádiz por A. M ${ }^{\mathrm{a}}$ Gordillo, Calcolítico de Cádiz por A. Álvarez, río Corbones por I. Rodríguez Temiño, Benaocaz por L.J. Guerrero Misa, Sanlúcar-Trebujena por $\mathrm{M}^{\mathrm{a}} \mathrm{L}$. Lavado, megalitismo de Cádiz por Regina Rodríguez, Barbate por A. Bernabé, Chipiona-Rota por F.J. Riesgo, Arcos de la Frontera por L. Perdigones, Paleolítico de Huelva por J. Castiñeira, Almadén de la Plata-Real de la Jara por M.A. Vegas, Bronce de Los Alcores por A. Jiménez, Palos de la Frontera por F. Pozo, Paleolítico del Bajo Guadalquivir por J.A. Caro, Osuna por J. Salas, habiendo sido publicadas 8: Alcalá de Guadaira (Buero y Florido 1999), Acueducto de Itálica (Canto 1979), Montellano (Oria y otros 1990), Alcores (Amores 1982), Lebrija (Caro 1991), Campiña sevillana (Ruiz Delgado 1985), Huelva N.W. (Pérez Macías 1987), Sevilla (Campos 1986) y Fuentes de Andalucía (Fernández Caro 1992).

Respecto a las tesis doctorales, fueron leídas 18 entre 1983 y 1992, fecha de mi jubilación, de las cuales 7 corresponden a Prehistoria (R. Cabrero, V. Hurtado, R. Cruz-Auñón, A. Ciudad, E. Rivero, J. Ramos y J.J. Fernández Caro), 6 a Protohistoria (M.L. de la Bandera, F. Amores, J.L. Escacena, A. Caro, M. Ma Ruiz y J.M. Campos) y 5 a Arqueología romana y medieval ( $R$. Corzo, J.J. Ventura, P. Caldera, J.A. de la Sierra y M. Oria). Estas tesis fueron dirigidas 8 por M. Pellicer, 3 por P. Acosta, 2 por E. Vallespí, 2 por P. León y 2 por F. Chaves.

A mi llegada a Sevilla la biblioteca del departamento era, en general, deficiente y fragmentaria, con grandes lagunas, careciendo de la bibliografía más elemental de Prehistoria. Sorprendentemente el contiguo departamento de Historia Antigua conservaba un rico lote bibliográfico de Arqueología que fue cambiado por lo existente de Historia Antigua en el nuestro. En un decenio se compraron abundantes fondos de Arqueología 
y particularmente de Prehistoria, absolutamente necesarios para la investigación.

El nutrido grupo de profesores y doctores formados en el departamento prosiguieron sus investigaciones arqueológicas con excelentes resultados, publicando trabajos de campo y de biblioteca, abarcando un completo arco científico, particularmente relativo a Andalucía occidental desde el Paleolítico hasta la romanización. Entre los investigadores y sus especialidades cabría enumerar en Paleolítico a E. Vallespí, J. Ramos y J. Fernández Caro; en Neolítico a P. Acosta, J.L. Escacena, J.C. Martín y J. Ramos; en Calcolítico a P. Acosta, V. Hurtado, R. Cabrero, E. Rivero, R. CruzAuñón y M. Puya; en Bronce a J.L. Escacena, J.C. Martín, L. García y M. Hunt; en fenicio a D. Ruiz Mata, A. Tejera, I. Negueruela, L. Perdigones y A. Muñoz; en período orientalizante a M. Bendala, J.M. Luzón, F. Chaves, M.L. de la Bandera, Ma Belén, D. Ruiz Mata, F. Amores, J.L. Escacena, M. Ma Ruiz Delgado, J. Fernández Jurado, J. Campos, P. Rufete, J.A. Pérez Macias, P. Florido y S. Buero; en turdetano a J.L. Escacena, A. Caro, M.L. de la Bandera, J. Fernández Jurado, P. Rufete, E. Ferrer Albelda, E. García Vargas, F.J. García Fernández; en romano a J.M. Luzón, P. León, F. Chaves, A. Canto, M. Bendala, J. Campos, E. García Vargas, R. Corzo y J.M. Rodríguez Hidalgo, entre otros.

Cabria aquí enumerar todo el acervo bibliográfico e historiográfico producido por el departamento en los últimos veinte años, pero esta prolija enumeración cae fuera de nuestro cometido.

Puesto que la misión del profesorado universitario es la docencia y la investigación, los profesores A. Díaz Tejera, director del Departamento de Filología Clásica, y A. Blanco, director del Departamento de Prehistoria y Arqueología, habían creado en 1969 la revista científica Habis. Al hacerme cargo de la dirección del departamento en 1975, fui nombrado junto con F. Presedo, director del Departamento de Historia Antigua, miembro del consejo redactor de la revista. En 1978 la revista correspondía a los tres departamentos, pero en 1981, por decisión unilateral de los departamentos de Filología Clásica y de Historia Antigua, la Prehistoria lamentablemente fue eliminada de la revista. Diez años después, el Departamento de Prehistoria y Arqueología afortunadamente logró crear se nueva revista Spal, bajo la dirección de E. Vallespí, que tan elevados frutos está dando.

Los arqueólogos formados en el departamento fueron colocándose en diferentes puestos de trabajo, nueve como catedráticos de las universidades Complutense y
Autónoma de Madrid, Sevilla, Córdoba, Cádiz, Huelva y La Laguna, 17 como profesores titulares en las universidades de Sevilla, Cádiz y Huelva, 6 como conservadores de los museos arqueológicos de Sevilla, Cádiz, Carmona y Cartagena, 18 en delegaciones culturales de la Junta de Andalucía, 7 en instituciones culturales públicas de Sevilla, Cádiz y Huelva, varios como profesores de institutos de enseñanza media.

En los años noventa tuvo lugar un arbitrario cambio político en la autorización de excavaciones arqueológicas por parte de la Dirección General de Bienes Culturales, al limitar o no autorizar la investigación de campo y potenciar las excavaciones urbanas, subvencionadas por los contratistas constructores. Los departamentos de Arqueología de las universidades andaluzas se vieron privados de sus proyectos de investigaciones en el campo. Esta actitud política significa un directo e irracional atropello a la Arqueología y a la cultura andaluza por parte de la Consejería de Cultura de la Junta de Andalucía.

En 1992, al cumplir 65 años, después de 40 años de docencia en investigación en las universidades de Zaragoza, Granada, Complutense de Madrid, La Laguna y Sevilla, mediante un arbitrario decreto, poco después derogado, me jubilé, siendo nombrado profesor emérito vitalicio de la Universidad de Sevilla, prosiguiendo como docente durante una docena de años y todavía como investigador.

Finalmente debo manifestar que me siento satisfecho y orgulloso de haber contribuido con el trabajo y esfuerzo mío y de mis colegas a elevar la calidad científica del Departamento de Prehistoria y Arqueología de la Universidad de Sevilla.

\section{BIBLIOGRAFÍA}

ACOSTA, P. (1983): "Estado actual de la prehistoria andaluza: Neolítico y calcolítico", Habis 14: 195-205.

- (1986): "El neolítico en Andalucía occidental. Estado actual”, Homenaje a Luis Siret: 136-151. Sevilla.

- (1980): "Avance de la estratigrafía de la Cueva de la Dehesilla (Algar, Cádiz)", IV Cogr.Arq. Faro.

- (1987): "El neolítico antiguo en el Suroeste español: La Cueva de la Dehesilla (Cádiz)", Colloque Int. C.N.R. S. Montpellier: 653-659. Paris.

ACOSTA, P.; CABRERO, R.; CRUZ-AUÑÓN, R. y HURTADO, V. (1987): "Informe preliminar sobre las excavaciones de la Morita (Cantillana, Sevilla)", Anuario Arqueológico de Andalucía 1985 II: $150-152$. 
ACOSTA, P. y PELLICER, M. (1990): La cueva de la Dehesilla (Jerez de la Frontera). Las primeras civilizaciones productoras en Andalucía Occidental. Jerez de la Frontera.

AMORES, F. (1982): Carta arqueológica de los Alcores (Sevilla). Sevilla.

AMORES, F. y otros (1997): “Excavación sistemática en la necrópolis de la Cruz del Negro (Carmona, Sevilla)", Anuario Arqueológico de Andalucía 1993 II: $154-158$.

- (1999): "Intervención de urgencia en el yacimiento de la Cruz del Negro (Carmona, Sevilla)", Anuario Arqueológico de Andalucía 1995 III: 513-516.

- (2001): "Intervención de urgencia en el yacimiento de la Cruz del Negro (Carmona, Sevilla)", Anuario Arqueológico de Andalucía 1997 III: 540-544.

AUBET, M.E. (1993): "Maluquer y el Carambolo", Tabona VIII, 2: 329-349.

BANDERA, M. L. de la (1982): “Orfebrería: Técnicas y tipología”, Boletín del Museo de Cádiz 3.

- (1989): La joyería prerromana en la provincia de Sevilla (Arte Hispalense 49). Sevilla.

BANDERA, M. L. DE LA y otros (1995): “El yacimiento tartésico de Montemolín”, Tartessos 25 años después: 315-332. Jerez de la Frontera.

BANDERA, M. L. DE LA y FERRER, E. (2002): "Secuencia estratigráfica tartesia y turdetana de Vico (Marchena, Sevilla)", Spal 11: 121-150. http:// dx.doi.org/10.12795/spal.2002.i11.06

BELÉN, Ma (1976): "Estudio y tipología de la cerámica gris en la provincia de Huelva", RABM LXXIX, 2: 353-388.

- (1987): "Mil años de historia de Coria: La ciudad prerromana", Azotea 11-12: 35-62.

- (1993): "El yacimiento tartésico de Niebla (Huelva)" Tartessos 25 años después: 359-389. Jerez de la Frontera.

- (1994): "Carmona prerromana, I milenio a.C.", Ciudades prerromanas en la Península Ibérica III: 20-27. Madrid.

- (2006): "Ánforas de los siglos VI-IV a.C. en Turdetania”, Spal 15: 217-246. http://dx.doi. org/10.12795/spal.2006.i15.11

BELÉN, Ma y otros (1983): "Excavaciones en Niebla (Huelva)", XVI CNA: 971-994. Zaragoza.

- (1997): Arqueología en Carmona (Sevilla). Excavaciones en la casa-palacio del Marqués de Saltillo. Sevilla.

BENDALA, M. (1975): “Un templo en Itálica de época republicana”, XIII CNA: 861-868. Zaragoza.
- (1982): "Excavaciones en el Cerro de los Palacios Itálica (Santiponce, Sevilla)", EAE 121: 29-73. Madrid.

BENDALA, M. y BELÉN, Ma (Coord.)(2007): El nacimiento de la Ciudad: La Carmona Protohistórica. $V$ Congreso de Historia de Carmona. Carmona.

BLANCO, A. (1956): "Orientalia I. Estudio de objetos fenicios y orientalizantes en la Península", AEspA 29: 3-51.

- (1960): “Orientalia II", AEspA 33: 3-43.

- (1964): "El problema de Tartessos", II Congreso de Estudios Clásicos: 551-589. Madrid.

- (1975): "Un nuevo mosaico italicense: El de Neptuno y los Pigmeos", XIII CNA: 917-920. Zaragoza.

- (1978): Mosaicos romanos de Itálica I. Corpus Mosaicos Romanos España II. Madrid.

- (1980): "Tartessos", Historia de España 1. Historia 16 (Extra 12): 75-88.

- (1984): "Mineros y metalúrgicos en Huelva", Investigación y Ciencia 90: 100-109. Barcelona.

BLANCO, A. y LUZÓN, J.M. (1974): El mosaico de Neptuno en Itálica.- Sevilla-

- (1975): "Resultado de las excavaciones del primitivo poblado de Riotinto", Huelva. Prehistoria y Antigüedad: 235-247. Huelva.

BLANCO, A.; LUZÓN, J.Mª y RUIZ MATA (1969): "Panorama tartésico en Andalucía Occidental", V Symposium de Prehistoria Peninsular: 119-162. Barcelona.

- (1970): "Excavaciones arqueológicas en el Cerro Salomón (Riotinto, Huelva)", Anales de la Universidad Hispalense 4. Sevilla.

BLANCO, A. y ROTHENBERG, B. (1981): Exploración arqueometalúrgica de Huelva. Barcelona.

- (1982): "Excavaciones en Tejada la Vieja", Exploración arqueometalúrgica de Huelva: 229281. Barcelona.

BLANCO, A. y otros (1985): “Tartessos", Cuadernos Historia 16: 3-40. Madrid.

BOESNECK, J. y VON DEN DRIESCH, A. (1980): Tierknochenfunde aus vier südspanischen Höhlen. Studien über Tierknochenfunde 7. München.

BUERO, M.S. (1984): Los motivos naturalistas en la cerámica pintada del bronce final del suroeste peninsular.- Habis 15, 345-364.

BUERO, M.S. y FLORIDO, P. (1999): Arqueología de Alcalá de Guadaira. Alcalá de Guadaira.

CABALlOS, A. (1994): Itálica y los italicenses. Aproximación a su historia. Sevilla. 
CABRERO, R. (1985): Aproximación al conocimiento del megalitismo en Andalucía Occidental. Prehistoria 2.

- (1986): "El megalitismo en la provincia de Huelva, I", Huelva en su historia: 83-148.

- (1988): "El megalitismo en la provincia de Huelva, II", Huelva en su historia 2: 57-118.

- (1988): El yacimiento calcolítico de Los Delgados, Fuente Ovejuna (Córdoba). Córdoba.

CABRERO, R. y FLORIDO, P. (1988): “Un importante enclave arqueológico de la Edad del bronce, Castillo de las Guardas (Sevilla)", I Congreso Nacional Cuenca Minera de Riotinto: 1-18.

CAMPOS, J. (1986): Excavaciones arqueológicas en la ciudad de Sevilla. El origen prerromano y la ciudad romana. Sevilla.

CAMPOS, J. y otros (1988): Protohistoria de la ciudad de Sevilla. Sevilla.

CANTO, A. (1979): "El acueducto romano de Itálica", MM 20: 282-338.

- (1982): "Excavaciones en el Pradillo (Itálica), un barrio tardío", EAE 121: 225-242.

CARO, A. (1991): Lebrija. La ciudad y su entorno (Prehistoria y protohistoria). Sanlúcar de Barrameda.

- (1995): "Contribución a la protohistoria del Bajo Guadalquivir. El área de Lebrija (Sevilla)”, Tartessos 25 años después: 333-358. Jerez de la Frontera.

CARO, A.; ACOSTA, P. y ESCACENA, J.L. (1987): "Informe sobre la prospección arqueológica con sonde estratigráfico en el solar de la calle Alcazaba (Lebrija, Sevilla)", Anuario Arqueológico de Andalucía 1986 II: 168-174.

CARRASCO, F. y otros (1993): Geología de la Cueva de Nerja. Trabajos sobre la Cueva de Nerja 3. Málaga.

CARRIAZO, J.M. (1935): "Estado actual de las excavaciones en Itálica. La manzana del Gymnasio", Anuario del Cuerpo Facultativo de Archiveros, Bibliotecarios y Arqueólogos III.

- (1935): "Les fouilles d'Italica. Aperçu historique", Bulletin de l'Office Int. des Instituts d'Archeologie et Histoire de l'Art I, 3 : 25-33. Paris.

- (1947): "La Edad del Bronce", Historia de España dirigida por Menéndez Pidal I, 1: 755-852. Madrid.

- (1959): "Gold of Tarschich? A treasure of prehistoric goldwork found near Sevilla", The Illustrated London News (31 Enero).

- (1960): "El mensaje de Tartessos", Anales de la Universidad Hispalense XXI, 1: 21-40.

- (1961): Invitación a Itálica. Sevilla.
- (1963): Itálica. Sevilla.

- (1970): El tesoro y las primeras excavaciones en el Carambolo. EAE 68. Madrid.

- (1973): Tartessos y el Carambolo. Madrid.

- (1980): Protohistoria de Sevilla. Sevilla.

CARRIAZO, J.M. y RADDATZ, K. (1960): "Primicias de un corte estratigráfico en Carmona", Archivo Hispalense 103-104: 333-369. Sevilla.

- (1961): "Ergebnisse einer ersten stratigraphischen Untersuchung in Carmona", MM 2: 71-106.

CAVA, A. (1997): "La industria lítica tallada de la Cueva de Nerja", Trabajos sobre la Cueva de Nerja 6: 225-250. Málaga.

CERDÁN, C. y LEISNER, G y V. (1952): "Los sepulcros megalíticos de Huelva", Informes y Memorias de la Comisaría General de Excavaciones Arqueológicas 26. Madrid.

CHAVES, F. (1978): "Las monedas halladas en unas cisternas italicenses", Habis 9: 465-469.

- (1980): "Monedas halladas en la campaña 1976 en el Cerro Macareno (Sevilla)", IV Congreso Nacional de Numismática: 165-167. Alicante.

CHAVES, F. y BANDERA, Ma L. La (1991): “Aspectos de la urbanística en Andalucía Occidental en los siglos VII-VI a la luz del yacimiento de Montemolín (Marchena, Sevilla)", II Congresso Internacional di Studi Fenici e Punici II: 691-714. Roma.

CHAVES, F.; BANDERA, M.L. de la; FERRER, E. y BERNÁLDEZ, E. (2000): "El complejo sacrificial de Montemolín”, IV Congreso Internacional de Estudios Fenicios y Púnicos II: 573-581. Cádiz.

COLLANTES DE TERÁN, F. (1977): Contribución al estudio de la topografía sevillana en la antigüedad y en la edad media. Sevilla.

CONRAD, H. C. y ROTHENBERG, B. (1980): Antikes Kupfer in Timna Tal. Bochum.

CORZO, R. (1982): “Organización del territorio y evolución urbana en Itálica”, EAE 121: 219-319. Madrid.

- (1993): "El teatro de Itálica", Teatros romanos de Hispania. Cuadernos de Arqueología Romana 2: 121-180. Granada.

CRUZ-AUÑÓN, R. y RIVERO E. (1987): Gilena, un foco de especial interés para el estudio de la edad del cobre en Andalucía. Sevilla.

DRIESCH, A. von den y otros (1985): Studien über frühe Tierknochenfunde der Iberischen Halbinsel 9. München.

ESCACENA, J.L. (1987): "Excavaciones en la Marismilla (Puebla del Río, Sevilla)", Anuario Arqueológico de Andalucía 1985 III: 296-298. 
ESCACENA, J.L.; RODRÍGUEZ DE ZULOAGA, M. y LADRÓN DE GUEVARA, I. (1996): Guadalquivir salobre. Elaboración prehistórica de sal marina en las antiguas bocas del río. Confederación Hidrográfica del Guadalquivir, Sevilla.

ESCACENA, J.L. y FRUTOS, G. de. (1985): "Estratigrafía de la Edad del Bronce en el Monte Berrueco (Medina Sidonia, Cádiz)", NAH 24: 9-70.

ESCACENA, J.L. e IZQUIERDO, R. (2001): "Arquitectura civil y religiosa en un barrio fenicio de Caura tartesia", Arquitectura oriental y orientalizante en la Península Ibérica: 123-157. Madrid.

ESCACENA. J.L.; IZQUIERDO, R. y CONDE, M. (2005): “Consagrado a Baal Saphón: un santuario fenicio en la antigua Caura", Azotea 15: 8-63.

FERNÁNDEZ CARO, J.J. (1992): Carta arqueológica del término de Fuentes de Andalucía. Fuentes de Andalucía.

- (2003): "El musteriense clásico de la paleoactividad del Cerro de Santisteban (Morón de la Frontera, Sevilla)", Spal 12: 53-80. http://dx.doi. org/10.12795/spal.2003.i12.02

FERNÁNDEZ FLORES, A. y RODRÍGUEZ, A. (2005): "Nuevas excavaciones en el Carambolo Alto, Camas (Sevilla)", III Simposio Internacional de Arqueología de Mérida II: 843-871.

FERNÁNDEZ GÓMEZ, F. y otros (1979): "Excavaciones en el Cerro Macareno, La Rinconada (Sevilla), NAH 7: 11-93.

FERNÁNDEZ JURADO, J. (1987): Tejada la Vieja, una ciudad protohistórica. Huelva Arqueológica IX (2 vol). Huelva.

FERNÁNDEZ JURADO, J. y otros (1990): Tartessos y Huelva. Huelva Arqueológica X-XI. Huelva.

FERRER ALBELDA, E. (1996): "Los púnicos de Iberia y la historiografía grecolatina", Spal 5: 115132. http://dx.doi.org/10.12795/spal.1996.i5.06

FERRER ALBELDA, E. y otros (coords.) (2007): Ilipa antigua. De la prehistoria a la época romana. Sevilla.

FLORIDO, P. (1984): “Ánforas prerromanas sudibéricas", Habis 15: 419-435.

- (1985): "Las ánforas del poblado orientalizante e ibero-púnico del Carambolo", Habis 16: 487-516.

GARCÍA BELLIDO, A. (1960): Colonia Aelia Augusta Itálica. Madrid.

— (1964): "Las casas de Itálica”, VIII CNA: 454-460.

GARCÍA FERNÁNDEZ, F.J. (2002): “Los turdetanos en la historiografía reciente", Spal 11: 219-231. http://dx.doi.org/10.12795/spal.2002.111.11
GARCÍA SÁNCHEZ, M. y JIMÉNEZ, S. (1995): “Los restos humanos de la Cueva de Nerja (Málaga)", Trabajos sobre la Cueva de Nerja 5: 403-424. Málaga. HOPF, Mª y PELLICER, M. (1970): "Neolithische Getreidefunde in der Höhle von Nerja (prov. Málaga)", MM 11: 18-34.

HUNT, M.A. (1995): "El foco metalúrgico de Aznalcóllar, Sevilla", Tartessos 25 años después: 447-473. Jerez de la Frontera.

HURTADO, V. (1985): "Excavación de una sepultura circular de la edad del bronce en Guadajira", Homenaje a Cánovas Pesini. Badajoz.

- (1991): "Informe de las excavaciones de urgencia en la Pijotilla", Extremadura Arqueológica II, 1: 31-43.

HURTADO, V, y AMORES, F. (1984): "El tholos de las Canteras y los enterramientos del bronce en la necrópolis de Gandul (Alcalá de Guadaira, Sevilla)", Cuadernos de Prehistoria de la Universidad de Granada 9: 147-174.

HURTADO, V. y GARCÍA, L. (1994): “Áreas funcionales en el poblado de Edad del Bronce de el Trastejón (Zufre, Huelva)" Arqueología en el entorno del Bajo Guadiana: 239-271. Huelva.

- (1994): "La necrópolis de Guadajira (Badajoz) y la transición a la edad del bronce en la cuenca media del Guadiana", Spal 3: 95-144. http://dx.doi. org/10.12795/spal.1994.i3.05

JORDÁ, F. y PELLICER, M. (coord.) (1986): Trabajos sobre la cueva de Nerja: General 1 Málaga.

KUKAHN, E. y BLANCO, A. (1959): "El tesoro del Carambolo", AEspA XXXII: 38-49.

LEISNER, G. y LEISNER, V. (1943): Die Megalithgraber der Iberischen Halbinsel. Der Süden. Berlin.

LEÓN, P. (1976): "Vasos procedentes de Itálica en la colección Lebrija", Habis 7: 265-270.

- (1983): "La zona monumental de la Nova Urbs (Itálica)", EAE 121: 97-132. Madrid.

- (1998): Traianeum de Itálica. Sevilla.

LUZÓN, J.Ma . (1973): Excavaciones en Itálica. Estratigrafia en el Pajar de Artillo. EAE 78. Madrid.

- (1975): La itálica de Adriano. Sevilla.

- (1982): "Consideraciones sobre la urbanística de la ciudad nueva de Itálica”, EAE 121: 75-95. Madrid.

LUZÓN, J.M ${ }^{\mathrm{a}}$ y RUIZ MATA, D. (1973): Las raíces de Córdoba. Estratigrafía en la Colina de los Quemados. Córdoba.

MALUQUER, J. (1992): "Excavaciones del Carambolo, Sevilla. Notas y experiencias personales", Clásicos de la Arqueología de Huelva 5. Huelva. 
MARTÍN DE LA CRUZ, J.C. (1976): "El corte F del Cerro Macareno, La Rinconada (Sevilla)", CUPAUAM 3: 9-32.

MARÍN, F. (1991): Biología (Trabajos sobre la Cueva de Nerja 2). Patronato de la Cueva de Nerja, Málaga.

MORALES, A. y PELLICER, M. (coord.) (1995): $L a$ fauna. Trabajos sobre la Cueva de Nerja 5. Málaga.

MUÑOZ, A. (1987): "Las ánforas prerromanas de Cádiz”, Anuario de Arqueología Andalucía 1985 II: 471-478.

NEGUERUELA, I. (1985): "Sobre la fecha de la necrópolis fenicia de Almuñécar", NAH 22: 193-210.

NIEMEYER, H. G., PELLICER, M y SCHUBART, H. (1964): "Ein altpunische Kolonie am der Mündung des Río Vélez", Arch. Anzeiger 3: 476-493. Berlin.

ORIA, M. y otros (1990): El poblamiento antiguo de la Sierra Sur de Sevilla: zona de Montellano. Sevilla.

PALANCAR, M. y otros (1983): "Saneamiento y abastecimiento de Itálica en la actualidad”, II Jornadas Est. Itálica Sevilla.

PELLICER, M. (1963): “Ein altpunisches Gräberfeld bei Almuñécar (prov. Granada)", MM 4: 9-38.

- (1963): Excavaciones en la necrópolis púnica "Laurita” del Cerro de San Cristóbal (Almuñécar, Granada). EAE 17.

- (1963): Estratigrafía prehistórica de la Cueva de Nerja. EAE 16. España.

- (1969): "La primeras cerámicas pintadas a torno andaluzas", Tartessos. V Simposio Internacional Prehistoria Peninsular: 291-310. Barcelona.

- (1969): "El yacimiento de los Toscanos y su contribución al estudio de las cerámicas pintadas hispanas protohistóricas", AEspA 42: 3-11.

- (1969): "Suchschnitte auf dem Peñón. Toscanos 64", MF 6: 4-11. Berlín.

- (1978): "Tipología y cronología de las ánforas prerromanas del Guadalquivir, según el Cerro Macareno", Habis 9: 365-400.

— (1982): "Las cerámicas del mundo fenicio del Bajo Guadalquivir: Evolución y cronología según el Cerro Macareno (Sevilla)", Madrider Beiträge 8: 371-402.

- (1982): "Excavaciones en Itálica: Muralla, cloacas y cisterna", EAE 121: 205-224. Madrid.

- (1983): "El yacimiento protohistórico de Quebrantahuesos (Riotinto, Huelva)", NAH 15: 61-90.

- (1998): "Los cortes estratigráficos de Itálica y su contribución al estudio de la dinámica históricocultural del yacimiento", Boletín Real Academia Bellas Artes de Santa Isabel de Hungría XXVI: 145-186. Sevilla.

- (1999): "Panorama de la arqueología de Itálica", Boletín Real Academia Bellas Artes de Santa Isabel de Hungría. Temas de Estética y Arte XIII: $175-$ 202. Sevilla.

PELLICER, M. y SCHÜLE, W. (1962): El cerro del Real, Galera (Granada). EAE 12.

- (1966): El Cerro del Real (Galera, Granada): El corte estratigráfico IX. EAE.

PELLICER, M. y otros (1966): Cerámica Española, de la prehistoria a nuestros días. Exposición. Madrid.

PELLICER, M. y HURTADO, V. (1980): El poblado metalúrgico de Chinflón (Zalamea la Real, Huelva). Sevilla.

PELLICER, M.; HURTADO, V. y BANDERA, Mª L. de la (1982): "El corte estratigráfico de la casa de la Venus", EAE 121: 11-28.

PELLICER, M. y ACOSTA, P. (1982): “El neolítico antiguo en Andalucía occidental", Colloque Int. Preh. Montpellier: 49-60.

PELLICER, M.; ESCACENA, J.L. y BENDALA, M. (1983): El cerro Macareno. EAE 124. Madrid.

PELLICER, M. y AMORES, F. (1985): "Protohistoria de Carmona. Los cortes estratigráficos CA-80 A y CA-80 B", NAH 22: 55-195.

PELLICER, M. y ACOSTA, P. (1997): El neolítico y calcolítico de la Cueva de Nerja en el contexto andaluz.- Trabajos sobre la Cueva de Nerja, 6. Málaga.

PERDIGONES, L. y otros (1990): La necrópolis fenicio-púnica de Cádiz. S. VI-IV a.C. Studia Punica 7. Roma.

PÉREZ MACÍAS, J.A. (1987): Carta arqueológica de los Picos de Aroche (Huelva).

- (1994): "Yacimiento calcolítico del Cerro del Berrueco (Picos de Aroche)", Arqueología en el entorno del Bajo Guadiana: 119-147. Huelva.

RÍOS, D. de los (1876): Plano topográfico de las ruinas de Itálica. Sevilla.

RIVERO, E. (1988): Análisis de las cuevas artificiales en Andalucía y Portugal. Sevilla.

RIVERO, E.; CRUZ-AUÑÓN, R y GARCÍA, F.M. (1988): "Nuevos datos sobre el megalitismo onubense: Necrópolis de Berrocal", Huelva en su Historia 2.

RIVERO, E. y otros (1989): "Avance de los trabajos realizados en el yacimiento de la edad del cobre de Negrón (Gilena, Sevilla)", XIX CNA.

RODANÉS, J.M. (1997): "La industria ósea de la Cueva de Nerja", Trabajos sobre la Cueva de Nerja 6: 203-224. Málaga.

RODRÍGUEZ HIDALGO, J.M. (1997): "La nueva imagen de la Itálica de Adriano", Itálica MMCC: 87-113. Sevilla.

ROOS, A. M (1982): “Acerca de la antigua cerámica gris a torno en la Península Ibérica”, Ampurias 44: 43-70. 
ROTHENBERG, B. (1972): Timna. London.

ROTHENBERG, B. y WEGNER, H. (1979): Le Sinaï. Berna.

RUFETE, P. (2002): El final de Tartessos en Huelva. Huelva Arqueológica 17. Huelva.

RUIZ DELGADO, M.Ma . (1985): Carta arqueológica de la Campiña Sevillana. Zona S.E.I. Sevilla.

- (1989): Fíbulas protohistóricas en el sur de la Península Ibérica. Sevilla.

RUIZ MATA, D.(1975): “Cerámicas del bronce del poblado de Valencina de la Concepción (Sevilla): Los platos", CuPAUAM 2: 123-150.

- (1986): "Las cerámicas fenicias del Castillo de Doña Blanca (Puerto de Santa María, Cádiz)", Los fenicios en la Península Ibérica. Aula Orientalis 3, I: 241-263.

SANCHIDRIÁN, J.L. (1994): Arte rupestre de la Cueva de Nerja. Trabajos de la Cueva de Nerja 4. Málaga.

SCHUBART, H.; NIEMEYER, H. G. y PELLICER, M. (1969): Toscanos, la factoría paleopúnica en la desembocadura del río Vélez. EAE 66.
SCHÜLE, W. y PELLICER, M. (1965): "Excavaciones en la zona de Galera (Granada)", VIII CNA: $387-$ 392.

TEJERA, A. (1975): “Orígenes y paralelos de las tumbas fenicias y púnicas de Andalucía”, Habis 6: 204208.

- (1977): "Huerto Pimentel (Lebrija, Sevilla): un poblado del Bronce Medio y Final en la Marisma del Guadalquivir", XV CNA.

- (1979): Las tumbas fenicias y púnicas del Mediterráneo Occidental. Sevilla.

VALLESPÍ, E. (1986): “El Paleolítico inferior y medio en Andalucía”, Homenaje a Luis Siret: 59-66. Sevilla.

- (1988): "Paleolítico medio de aspecto postachelense en la depresión superior del Guadalquivir", Homenaje a E. Ripoll. Uned Serie I, Prehistoria I: 85-91.

- (1995): "Prehistoria de Andalucía: Paleolítico y Epipaleolítico", II Congreso Internacional "El Estrecho de Gibraltar": 3-18.

WEGNER, H. (1954): Gymnasium (Plano de Itálica), 431. 